\title{
Recognizing and Supporting Students with Mental Health Disorders: The REDFLAGS Model
}

\author{
Michael T. Kalkbrenner, MS, NCC (Corresponding author) \\ Department of Counseling \& Human Services \\ Old Dominion University, 110 Education Building, Norfolk, Virginia 23529-0499, USA \\ Email: mkalk001@odu.edu
}

Received: August 11, 2015 Accepted: August 24, 2015 Published: September 6, 2015

doi:10.5296/jet.v3i1.8141 URL: http://dx.doi.org/10.5296/jet.v3i1.8141

\begin{abstract}
The increasing prevalence of Mental Health Disorders (MHDs) and campus violence tragedies has called attention to the issue of MHDs on college campuses. The current article provides an overview of the prevalence and severity of MHDs among college students. In addition, a review of the most common MHDs on college campuses is included. Students with MHDs are at increased risks for a variety of negative consequences. Students who received treatment for MHDs reported a more positive daily functioning and demonstrated significantly higher retention rates. However, a large proportion of the students who are living with MHDs do not receive treatment. Furthermore, college counselors typically only interact with a small proportion of the students who are living with MHDs. Faculty members have more frequent interactions with students and are a valuable resource for recognizing students who are living with MHDs. The REDFLAGS Model, an acronym that identifies eight behavioral indicators of MHDs in students is introduced. A description of how educators can use the REDFLAGS Model as a tool for recognizing signs of MHDs in their students is described. It is not recommended that educators provide treatment for MHDs to their students. Rather, educators can use The REDFLAGS Model to recognize signs of MHDs in students and support them by making referrals to the college counseling center or to other resources. A resource list of mental health support services that are available for college students is included. The resource list can be customized to include resources at specific universities in particular geographic areas.
\end{abstract}

Keywords: Mental Health Disorders, College Students, Higher Education 


\section{Introduction}

In the early morning hours of April 16, 2007, Seung-Hui Cho committed one of the most vicious school shootings in American history, murdering 32 people and severely wounding 17 others (Klienfield, 2007). Cho was a senior at Virginia Polytechnic Institute who had a history of untreated mental health issues. The specific reasons why Cho committed these murders are unclear. However, it is possible that mental health interventions could have prevented this disaster. The tragic events that took place at Virginia Poly-technic Institute have called attention to the issue of Mental Health Disorders (MHDs) on college campuses (Voelker, 2007). The prevalence and severity of MHDs among college students has been increasing over the past 50 years (Blanco et al., 2008; Erdur-Baker, Aberson, Barrow, \& Draper, 2006; Twenge et al., 2010; Wagner \& Davis, 2006; Zivin, Eisenberg, Gollust, \& Golberstein, 2009). Thus, the primary purposes of the current are:

1) To provide an overview of the prevalence and severity of MHDs on college campuses.

2) To introduce The REDFLAGS Model as a tool that educators and college administrators can use to recognize students who are living with MHDs.

3) To provide specific recommendations for how educators and other university personnel can support students who are living with MHDs.

\section{Increasing Prevalence of MHDs among College Students}

Attending college is a major life-transition, which can be stressful for students. This transitional period, coupled with the age at which most students attend college, places them at increased risks for developing MHDs (Blanco et al., 2008). Mental Health Disorders are most likely to manifest during young adulthood and approximately $50 \%$ of young adults institutions of higher education (Kessler et al., 2005; U.S. Department of Education, 2007). The term Mental Health Disorder refers to a "disturbance that causes clinically significant distress or impairment in social, occupational, or other important areas of functioning" (American Psychiatric Association, 2013, p. 21). An increasing number of college students are suffering from MHDs (Twenge et al., 2010; Zivin et al., 2009). From 1939 to 2007, college students' scores on the Minnesota Multiphasic Personality Inventory (MMPI) revealed that students were five times more likely to indicate the presence of mental health issues (Twenge et al., 2010). Similarly, Zivin et al. (2009) conducted a longitudinal study and found that one third of college students reported living with at least one MHD over a two-year period.

College students are also struggling with more severe and complex mental health issues (Benton, Robertson, Tseng, Newton, \& Benton, 2003; Gallagher, 2012; Gallagher \& Schwartz, 2006). A national survey of college counseling center directors indicated that $91.60 \%$ of participants reported that the prevalence, complexity, and severity of MHDs among college students were on the rise (Gallagher, 2012). In addition to the increasing severity of MHDs, there are particular MHDs that have become especially common among college students. 


\subsection{Most Prevalent MHDs among College Students}

Depression, anxiety, and Substance Use Disorders (SUDs), are some of the most prevalent MHDs on college campuses (American College Health Association, 2011; Benton et al., 2003; Baez, 2005; Blanco et al., 2008; Eisenberg, Gollust, Golberstein, \& Hefner, 2007; Green, Lowry, \& Kopta, 2003). One in three college students reported experiencing symptoms of depression that were severe enough to impair their ability to function (American College Health Association, 2011). Eisenberg, Gollust, Golberstein, and Hefner (2007) found that depression or anxiety was prevalent among $15.6 \%$ of undergraduate students and $13.0 \%$ of graduate students. Furthermore, Green, Lowry and Kopta (2003) found that $39 \%$ of college students who attended counseling at the university counseling center were living with depression.

The term Substance Abuse Disorders (SUDs) has been replaced with Addictive Disorders in the recently updated fifth edition of the Diagnostic and Statistical Manual of Mental Disorders (DSM) (American Psychiatric Association, 2013). However, the researchers of the existing studies on substance abuse were conducted before DSM was updated. Consequently, the term Substance abuse disorders will be used throughout the remainder of this paper. Substance Abuse Disorders, alcohol abuse in particular, are especially common among college students (Blanco et al., 2008; Knight et al., 2002; Rimsza \& Moses, 2005). Approximately $80 \%$ of college students reported consuming alcohol and $40 \%$ had engaged in binge drinking (Rimsza \& Moses, 2005). Students with MHDs were found to be at increased risk for a variety of biopsychosocial negative consequences (Keyes et al., 2012).

\subsection{College Students and Negative Consequences of MHDs}

Students who were living with MHDs are at increased risk for experiencing negative consequences, including academic impairments and suicidal behaviors (American College Health Association, 2011; Keyes et al., 2012). College students who were attending public four year universities that were living with a physical or mental disability were less likely to complete their bachelor's degrees, $28 \%$ compared to their classmates who were not living with a disability, 54\% (Steele \& Wolanin, 2004). Furthermore, students who were living with psychiatric disabilities were more likely to drop out of college compared to students who were living with other types of disabilities (Salzer, 2012). According to Unick, Snowden, and Hastings (2009) anxiety and depressive disorders are likely to occur co-morbidly and interfere with one's ability to function. Common negative consequences of both single and co-occurring anxiety and depressive disorders include: inability to concentrate, thoughts of suicide, unwanted sexual behavior, sleep difficulties, fatigue, depression, irritability, and feelings of worthlessness (Mackenzie et al., 2011; Unick et al., 2009). Substance use disorders have been found to exacerbate the negative consequences of co-occurring MHDs. Forty-six percent of community college students and $50 \%$ of four-year university students met the criteria for binge drinking (Blowers, 2009). Students who met the criteria for binge drinking were at a significant risk for hangover, poor test scores, trouble with police, damaged property, arguments, fights, missed classes, and driving under the influence of alcohol (Blowers, 2009). Students who received treatment for MHDs were significantly less likely to experience negative consequences (Bishop, 2010; Lucas, 2012). 


\subsection{Treatment for MHDs}

Students who received counseling for MHDs reported more positive daily functioning and demonstrated significantly higher academic retention rates compared to students who did not receive counseling (Bishop, 2010; Lucas, 2012). However, a large proportion of college students who are living with MHDs do not receive treatment (Eisenberg, Golberstein, \& Gollust, 2007). The specific reasons behind why a significant proportion of college students with MHDs do not seek treatment are unclear. However, findings from the literature suggest that there is a stigmatization of MHDs in American culture that contributes to the lack of help-seeking behaviors among individuals who are living with MHDs (Sickel, Nabors, \& Seacat, 2014). Furthermore, college students have been found to have adequate awareness about the symptoms of anxiety, depression, and SUDs; despite this awareness, students reported being largely unaware of the resources that are available for mental health disorders (Dobmeier et al., 2011; Dobmeier, Kalkbrenner, Hill, Hernández, 2013). More specifically, Dobmeier et al. (2013) found that 50\% $(n=57)$ of the college students in their sample were unaware of the mental health resources that were available to them on campus. Furthermore, students were especially unlikely to access university related resources (e.g., referral to the college counseling center and talking to a professor or resident advisor). Because of the combination of the stigmatization of MHDs, students' unawareness of resources for MHDs, and their reluctance to access counseling services, there is a need for college administrators, educators, and other university personnel to take leadership roles in recognizing and supporting students who are struggling with MHDs (Futo, 2011).

\section{Recognizing Signs of MHDs in Students: The REDFLAGS Model}

The early recognition of students who are showing signs of MHDs is essential to providing them with treatment and preventing campus violence incidents (Futo, 2011). Faculty members have frequent interactions with their students and are, therefore, a valuable resource for supporting students who are living with MHDs (Futo, 2011; Dobmeier et al., 2013). Educators can be a valuable first line of defense for recognizing and referring students who are living with MHDs to services (Dobmeier et al., 2013). However, it is unclear whether or not faculty members are adequately equipped to recognize the signs and symptoms of MHDs in their students. The REDFLAGS Model (see Figure 1) is an acronym that identifies eight behavioral indicators of MHDs in students. College administrators and other university personnel can distribute The REDFLAGS Model to faculty members to be used as a tool for recognizing signs of MHDs in their students.

\subsection{Components of the REDFLAGS Model}

The warning signs on The REDFLAGS Model are not specific to particular MHDs as the model was not designed to be a diagnostic instrument for detecting specific MHDs. The warning signs on The REDFLAGS Model are general and common symptoms of MHDs specifically among college students that were identified from (The American Psychiatric Association, 2013; Barr, 2014; Gecker, 2007). More specifically, the model was created by compiling common symptoms of MHDs in college students that were identified by Barr (2007) and Gecker (2007). The identified symptoms were then confirmed by 
cross-referencing them with the fifth edition of the Diagnostic and Statistical Manual of Mental Disorders (DSM) (American Psychiatric Association, 2013). Confirming the characteristics of each component on The RED FLAGS model with the criteria in the DSM supports the validity of the model because the DSM is a widely used manual for identifying symptoms of MHDs (American Psychiatric Association, 2013).



Figure 1. The REDFLAGS Model

The REDFLAGS Model is an acronym that highlights eight warning signs that suggest a student might be struggling with an MHD. The REDFLAGS Model should not be used to diagnose a student with an MHD. Rather, the model is intended to be used by faculty and other college administrators as a tool for identifying students who might be struggling with mental health concerns.

The first component of The REDFLAGS Model includes recurrent class absences that occur suddenly and are uncharacteristic of the student. If, for example, a student with perfect attendance abruptly begins missing multiple classes. The second behavioral indicator of an MHD is student who displays extreme or unusual emotional reactions that are out of context for the situation (Gecker, 2007). For example, a student who abruptly begins crying or yelling during a standard class discussion. The third warning sign is a student who exhibits difficulty concentrating on frequent occasions which indicates that he or she might be showing a sign 
of an MHD (Gecker, 2007). For example, a student who frequently has difficulty concentrating during class lectures, discussions, group work, or while watching educational videos. The fourth warning sign on The REDFLAGS Model is a display of frequent anxiety or worry about course assignments, which could indicate that a student is struggling with a MHD (Barr, 2014).

The fifth warning sign is a student who uncharacteristically begins turning in late assignments, which might suggest that the student is struggling with an MHD (Barr, 2014). The sixth behavioral indicator is a neglect of personal appearance and hygiene. Neglecting personal hygiene is an indicator of mental illness (American Psychiatric Association, 2013). In particular, if a student appears uncharacteristically disheveled on frequent occasions. The seventh warning sign on The REDFLAGS Model is when a faculty member has a gut instinct that a student is struggling with a mental health issue. Gecker, (2007) and the current author recommend that educators trust their instincts. An educator's intuition that a student is struggling with a mental health issue could be correct (Gecker, 2007). The last warning sign on The REDFLAGS Model is a sudden deterioration in the quality of a student's work or the content of assignments becomes dark or negative. If, for example, in a writing assignment a student describes feeling hopeless or suicidal.

\subsection{Using the REDFLAGS Model}

College students typically experience fluctuations in mood (Sax, Bryant, \& Gilmartin, 2004). A student who displays a single warning sign of an MHD on The REDFLAGS Model in isolation is less likely to be struggling with an MHD compared to another a student who is displaying multiple warning signs. However, there is not a discrete number of warning signs that indicate that is a student is living with an MHD. The number, frequency, and intensity of a student's REDFLAGS should be taken into account when considering if that student is at risk for an MHD. If an educator recognizes a potential warning sign of an MHD in a student and is uncertain about how to proceed, it is recommended that the educator either checks in with the student or consults with a college or college counselor about the possible concern (Futo, 2011). It is recommended that college counselors make themselves available to faculty members for consultation. Tragedies like the one that transpired at Virginia Poly-technic Institute highlighted the risk of ignoring possible warning signs that a student is suffering from mental health issues. If a student might be showing signs of an MHD, it is better for educators to be cautious and check in with the student or communicate their concern to a counselor to ensure the safety of that student and others (Futo, 2011).

\section{Implications for Education and Training}

College counseling centers are typically the only resource on college campuses that provide in-depth mental health services and are a valuable resources for students who are living MHDs (Brack, Runco, Cadwallader, \& Kelley, 2012). However, a large proportion of college students with MHDs are unaware of the counseling services that are available to them on campus (Dobmeier et al., 2013). Furthermore, college counselors typically have interactions with only a small proportion of the students on campus who are living with MHDs (Eisenberg et al., 2007). The REDFLAGS Model can be used by faculty members and other 
university personnel who have more frequent interactions with students to recognize signs of MHDs. It is not recommended that educators should providetreatment for MHDs to their students. Rather, educators can use The REDFLAGS Model to recognize warning signs of MHDs in their students. Faculty members can then provide initial support to students by referring them to support services.

University administrators can easily distribute The REDFLAGS Model to faculty members to be used as a tool for identifying students who might be struggling with MHDs. College counselors can support faculty members by explaining the components of The REDFLAGS Model and making themselves available for consultation. For example, explaining that if a faculty member believes that a student is showing signs of an MHD, he or she can take one of the following courses of action: talk to the student, refer the student to resources, or discuss their concerns about the student with a colleague or college counselor (Barr, 2014; Gecker, 2007). Furthermore, faculty members should be advised that if they decide to talk to a student about a possible mental health concern, the educator should speak to the student privately and in a non-judgmental manner (Barr, 2014). For example, "It seems as if you are having a rough time" or "I sense that you are really stressed out" (Barr, 2014, p.36). These are supportive and non-judgmental statements that show a genuine concern for the student's wellbeing and increases the chances that the student will be receptive (Barr, 2014). Faculty members should also have a list of resources available before discussing MHD related concerns with a student. See Figure 2 for a list of resources for MHDs that are available to college students. Faculty members should be advised to consult with a college counselor when feeling uncertain or uncomfortable discussing an MHD related concern with a student.

\subsection{Increasing Students'Awareness of Resources}

Previous research has found that college students were unaware of the university related resources that were available for MHDs (Dobmeier et al., 2011; Dobmeier et al., 2013). In addition to using The REDFLAGS model, it is recommended that college administrators and other university personnel implement the following awareness strategies that were suggested by Dobmeier et al. (2013)

1) Provide information and tours of the campus counseling center and health center during freshmen orientation.

2) Offer training to faculty and residential staff on recognizing behavioral signs of mental health problems.

3) Engage residence directors in presenting to students how to ask for help for oneself or a friend with a mental health problem.

4) Consult with faculty and staff in the development of policies and procedures for seeking help for at-risk students, including referring a student to the counseling center.

5) Engage students in focus groups about their reticence to turn to the counseling center, health center, faculty, or residence staff for help with a mental health problem.

6) In consultation with students, develop a workshop module for off-campus mental health 
resources available to students.

7) Engage upperclassmen and women to help conduct workshops as help-seeking and help-giving role models.

8) Include the phone number and a website link to the college counseling center on the back of residential student identification cards. (24-25).

\section{Resource Lists}

Resource lists can also be used to increase students' awareness of the mental health support services that are available to them. Resource lists provide a central directory that students can access to gain awareness about the support services that are available to them. It is recommended that faculty members include a resource list on the last page of their course syllabi (See Figure 2).

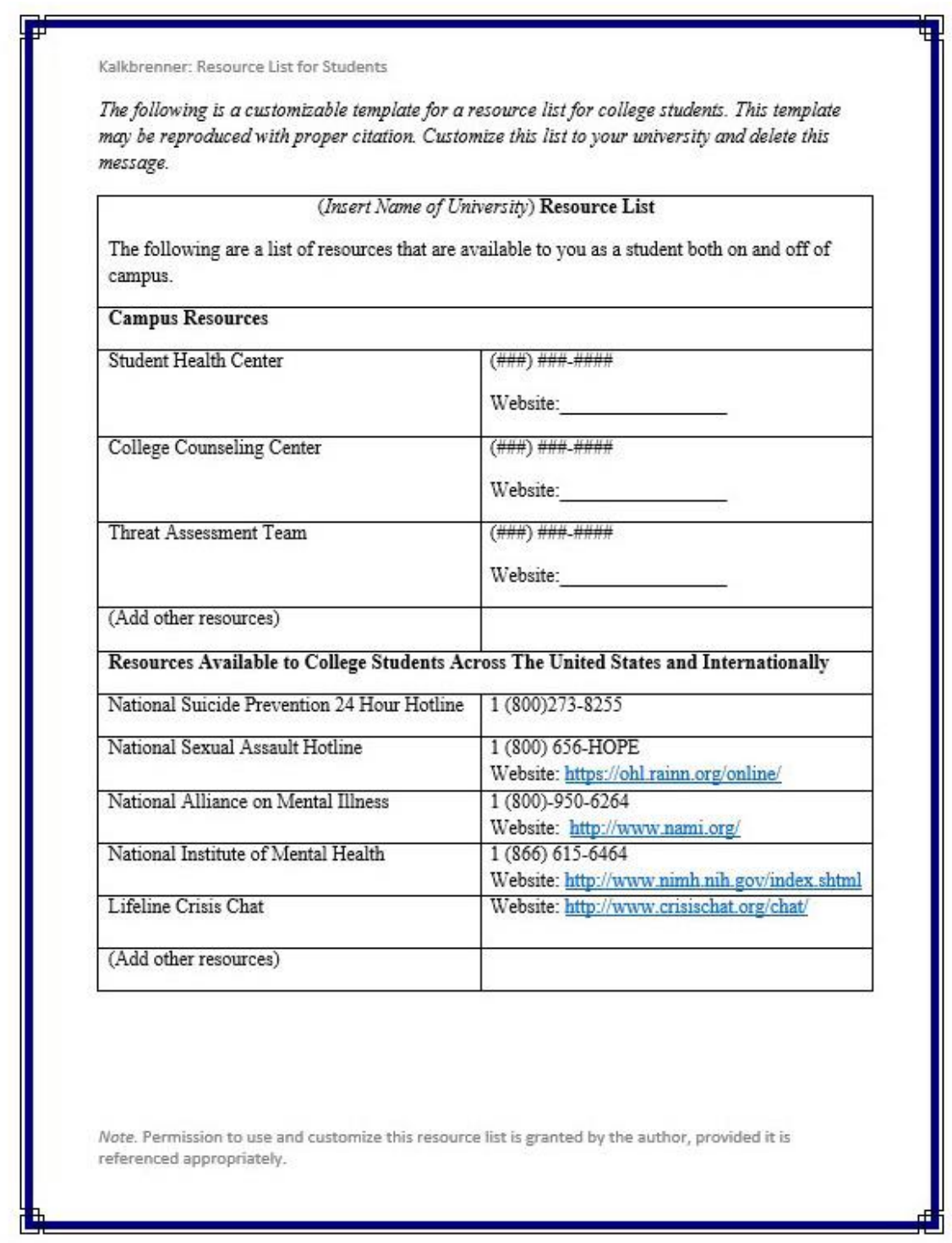

Figure 2. Customizable Resource List 
This resource list can be customized to represent the specific resources that are available to students at a particular university. This resource list can be used by students to access a variety of resources that are available to them both on and off of campus. A customizable version of this resource list is available for download free of charge at the following weblink: https://drive.google.com/a/odu.edu/file/d/0B3Gq0WAQ-x8ENFR1S2dDV2xkVXc/view?usp= sharing

The first portion of the resource list includes a template that can be customized to include the resources at a specific university in a particular community. There are recommended resources that are available on most college campuses which include the: student health center, college counseling center, and threat assessment team. This resource list template is customizable and allows for modification of the existing resources in the event that a particular university does not offer one of the previously suggested resources. The template also allows educators and other university employees to add additional university-specific resources to the list.

The second portion of the resource list includes online resources and chat rooms that are available to college students across the United States and internationally. This section can also be customized as users might add additional online resources at their discretion. In addition to inclusion in course syllabi, resource lists can be posted in the flowing campus locations: student union, health center, student living quarters, bulletin boards in academic buildings, and on campus websites. See Figure 2 for a weblink to this customizable resource list is available for download free of charge.

\section{Limitations \& Future Research}

Mental health disorders can sometimes present in complex ways (Wilson, 2014). Some faculty members might not have adequate training to recognize the warning signs that are included on The REDFLAGS Model. Consequently, it is recommended that educators receive additional training for how recognize signs and symptoms of MHDs in their students. Future research is needed to identify additional strategies for further training faculty members to recognize the signs and symptoms of MHDs in their students.

Some faculty members might be uncomfortable or even unwilling to serve as a first line of defense by recognizing students who could be showing signs of MHDs. However, faculty members and other university personnel have a responsibility to support students who are living with MHDs (Futo, 2011). It is recommended that new faculty member orientations include information about the prevalence and severity of MHDs among college students. Furthermore, The REDFLAGS Model cannot be used as a diagnostic instrument. The REDFLAGS Model was designed to be an accessible and straightforward tool that can be used by educators and other university personnel to recognize students who might be struggling with MHDs. Future research is needed to develop instruments for diagnosing specific MHDs in college students. 


\section{Conclusion}

As the prevalence and severity of MHDs increases among college students, there is a growing need for support services. The early identification of students who are living with MHDs is essential to prevent future tragedies resembling the one that occurred at Virginia Poly-technic Institute. College administrators must collaborate with faculty members and other university personnel to recognize and refer students with MHDs to resources (Futo, 2011). According to Futo, (2011)

"every university or college community member must step up and take responsibility for their safety and the safety of others by educating themselves on the early warning signs that someone is in crisis, by having the courage to speak up when they notice signs and ensuring appropriate referrals are made" (p.28).

Faculty members have frequent contact with their students and are a valuable first line of defense for recognizing students who are living with MHDs (Futo, 2011; Dobmeier et al., 2013). The REDFLAGS Model is an acronym of eight behavioral indicators that a student might be struggling with a MHD. The REDFLAGS model can be distributed to educators and be used as a tool for recognizing students who are struggling with MHDs. Once at-risk students are identified, educators can support students by referring them to resources or discussing their concerns with a college counselor. Recognizing and supporting students who are living with MHDs will most likely lead to a reduction in the incidence of campus violence tragedies and lead to an overall increase in students' wellbeing.

\section{References}

American College Health Association. (2011). ACHA-national college health assessment II: Reference group executive summary Spring 2011. Hanover, MD: Author.

American Psychiatric Association. (2013). Diagnostic and statistical manual of mental disorders (5th ed.). Arlington, VA.

Baez, T. (2005). Evidenced-based practice for anxiety disorders in college mental health. Journal of College Student Psychotherapy, 20, 33-48. http://dx.doi.org/10.1300/J035v20n01_04

Barr, B. (2014). Identifying and Addressing the Mental Health Needs of Online Students in Higher Education. Online Journal of Distance Learning Administration, 17(2), 35-40.

Benton, S. A., Robertson, J. M., Tseng, W.-C., Newton, F. B., \& Benton, S. L. (2003). Changes in counseling center client problems across 13 years. Professional Psychology: Research and Practice, 34, 66-72. http://dx.doi.org/10.1037/0735-7028.34.1.66

Bishop, J. B. (2010). The counseling center: An undervalued resource in recruitment, retention, and risk management. Journal of College Student Psychotherapy, 24(4), 248-260. http://dx.doi.org/10.1037/0735-7028.34.1.66

Blanco, C., Okuda, M., Wright, C., Hasin, D. S., Grant, B. F., Liu, S.-M., \& Olfson, M. (2008). Mental health of college students and their non-college-attending peers: Results from the national epidemiologic study on alcohol and related conditions. Archives of General 
Psychiatry, 65, 1429-1437. http://dx.doi.org/10.1080/87568225.2010.509219

Brack, A. B., Runco, D. V., Cadwallader, L. A., \& Kelley, M. (2012). An exploratory study of undergraduate students' referral preferences. Journal of College Student Psychotherapy, 26, 155-162.

Dobmeier, R. A., Hernández, T. J., Barrell, R. G., Burke, D. M., Catlin-Rakoski, S. J., Hanna, C. M., ... \& Siclare, M. (2011). Student knowledge of signs, risk factors, and resources for depression, anxiety, sleep disorders, and other mental health problems on campus. CSPA-NYS Journal of Student Affairs, 11, 103-122.

Dobmeier, R. A., Kalkbrenner, M. T., Hill, T, T., \& Hernández, T. J. (2013). Residential community college student awareness of mental health problems and resources. CSPA-NYS Journal of Student Affairs, 13, 15-28.

Eisenberg, D., Golberstein, E., \& Gollust, S. E. (2007). Help-seeking and access to mental health care in a university student population. Medical Care, 4(5), 594-601. http://dx.doi.org/ 10.1097/MLR.0b013e31803bb4c1

Eisenberg, D., Gollust, S. E., Golberstein, E., \& Hefner, J. L. (2007). Prevalence and correlates of depression, anxiety, and suicidality among university students. The American Journal of Orthopsychiatry, 77(4), 534-542. http://dx.doi.rog/10.1037/0002-9432.77.4.534

Erdur-Baker, O., Aberson, C. L., Barrow, J. C., \& Draper, M. R. (2006). Nature and severity of college students' psychological concerns: A comparison of clinical and nonclinical national samples. Professional Psychology: Research and Practice, 37, 317-323. http://dx.doi.org/ 10.1037/0735-7028.37.3.317

Futo, J. (2011). Dealing with mental health issues on campus starts with early recognition and intervention. Campus Law Enforcement Journal, 41(3), 22-23.

Gallagher, R. P. (2012). Thirty years of the national survey of counseling center directors: A personal account. Journal of College Student Psychotherapy, 26, 172-184. http://dx.doi.org/10.1080/87568225.2012.685852

Gallagher, R. P., \& Schwartz, A. J. (2006). National survey of counseling center directors. Journal of American College Health, 54, 341-352.

Gecker, E. (2007). How do I know if my student is dangerous?. Academe, 93(6), 38-39.

Green, J. L., Lowry, J. L., \& Kopta, S. M. (2003). College students versus college counseling center clients: What are the differences? Journal of College Student Psychotherapy, 17, 25-37. http://dx.doi.org/10.1300/J035v17n04_05

Joyce, A. W., Ross, M. J., Vander Wal, J. S., \& Austin, C. C. (2009). College students' preferences for psychotherapy across depression, anxiety, relationship, and academic problems. Journal of College Student Psychotherapy, 23, 212-226. http://dx.doi.org/10.1080/ 87568220902794150

Kessler, R. C., Berglund, P., Demler, O., Jin, R., Merikangas, K. R., \& Walters, E. E. (2005). 
Lifetime prevalence and age-of-onset distributions of DSM-IV disorders in the national comorbidity survey replication. Archives of General Psychiatry, 62, 593-602. http://dx.doi.org/10.1001/archpsyc.62.6.593

Keyes, C. M., Eisenberg, D., Perry, G. S., Dube, S. R., Kroenke, K., \& Dhingra, S. S. (2012). The relationship of level of positive mental health with current mental disorders in predicting suicidal behavior and academic impairment in college students. Journal of American College Health, 60, 126-133. http://dx.doi.org/10.1080/07448481.2011.608393

Klienfield, N. R. (2007, April). Before deadly rage, a life consumed by a troubling silence. The New York Times. Retrieved from: http://www.nytimes.com/2007/04/22/us/22vatech.html? pagewanted=all

Knight, J. R., Wechsler, H., Kuo, M., Seibring, M., Weitzman, E. R., \& Schuckit, M. A. (2002). Alcohol abuse and dependence among U.S. college students. Journal of Studies on Alcohol, 63, 263-270. http://dx.doi.org/10.15288/jsa.2002.63.263

Kraft, D. P. (2009). Mens sana: The growth of mental health in the American College Health Association. Journal of American College Health, 58, 267-275. http://dx.doi.org/10.1080/ 07448480903297546

Mackenzie, S., Wiegel, J., Mundt, M., Brown, D., Saewyc, E., Heiligenstein, E., \& ... Fleming, M. (2011). Depression and suicide ideation among students accessing campus health care. American Journal of Orthopsychiatry, 81(1), 101-107. http://dx.doi.org/10.1111/j. 1939-0025.2010.01077.x

Musiat, P., Conrod, P., Treasure, J., Tylee, A., Williams, C., \& Schmidt, U. (2014). Targeted prevention of common mental health disorders in university students: Randomized controlled trial of a transdiagnostic trait-focused web-based intervention. Plos One, 9, 1-10. http://dx.doi.org/10.1371/journal.pone.0093621

Rimsza, M. E., \& Moses, K. S. (2005). Substance abuse on the college campus. Pediatric Clinics of North America, 52, 307. http://dx.doi.org/10.1016/j.pcl.2004.10.008

Salzer, M. S. (2012). A comparative study of campus experiences of college students with mental illnesses versus a general college sample. Journal of American College Health, 60(1), 1-7. http://dx.doi.org/10.1080/07448481.2011.552537

Sax, L. J., Bryant, A. N., \& Gilmartin, S. K. (2004). A longitudinal investigation of emotional health among male and female first-year college students. Journal of the First-Year Experience \& Students in Transition, 16(2), 39-65.

Sickel, A. E., Nabors, N. A., \& Seacat, J. D. (2014). Mental health stigma update: A review of consequences. Advances in Mental Health, 12(3), 202-215. http://dx.doi.org/10.1080/ 18374905.2014.11081898

Steele, P. E., Wolanin, T. R., \& Institute for Higher Education Policy, W. D. (2004). Higher Education opportunities for students with disabilities: A primer for policymakers. Institute for Higher Education Policy. Retrieved from: http://eric.ed.gov.proxy.lib.odu.edu/?id=ED485430 


\section{Macrothink}

Twenge, J. M., Gentile, B., DeWall, C. N., Ma, D., Lacefield, K., \& Schurtz, D. R. (2010). Birth cohort increases in psychopathology among young Americans, 1938-2007: A cross-temporal meta-analysis of the MMPI. Clinical Psychology Review, 30, 145-154. http://dx.doi.org/10.1016/j.cpr.2009.10.005

Unick, G., Snowden, L., \& Hastings, J. (2009). Heterogeneity in comorbidity between major depressive disorder and generalized anxiety disorder and its clinical consequences. Journal of Nervous \& Mental Disease, 197(4), 215-224. http://dx.doi.org/10.1097/NMD.0b013e3 $1819 \mathrm{~d} 954 \mathrm{f}$

Voelker, R. (2007). Campus tragedy prompts closer look at mental health of college students. Journal of the American Medical Association, 297, 2335-2337. http://dx.doi.org/10.1001/ jama.297.21.2335

Wagner, M., \& Davis, M. (2006). How are we preparing students with emotional disturbances for the transition to young adulthood? Findings from the National Longitudinal Transition Study 2. Journal of Emotional \& Behavioral Disorders, 14, 86-98. http://dx.doi.org/10. $1177 / 10634266060140020501$

Wilson, F. (2014). Classification and the clinician. Australian and New Zealand Journal of Psychiatry, 48(12), 1168-1169. http://dx.doi.org/10.1177/0004867414559135

Zivin, K., Eisenberg, D., Gollust, S. E., \& Golberstein, E. (2009). Persistence of mental health problems and needs in a college student population. Journal of Affective Disorders, 117, 180-185. http://dx.doi.org/10.1016/j.jad.2009.01.001

\section{Copyright Disclaimer}

Copyright reserved by the author(s).

This article is an open-access article distributed under the terms and conditions of the Creative Commons Attribution license (http://creativecommons.org/licenses/by/3.0/). 